\title{
Towards Sustainable Water Processes
}

\author{
Ilkka Pollari \\ Director, Product Stewardship \& Regulatory Affairs, Kemira Plc
}

\begin{abstract}
Megatrends of population growth, urbanization and global warming are making it more and more difficult to find clean water for our needs. Global demand for fresh water grows at 2$3 \% /$ year while availability of fresh water has not been increasing. Regional differences in the growth rates are big. The main sustainability objective in water processes is balancing the demand - supply equation. Human impact on the atmosphere seems to aggravate the water availability problem. Over two thirds of global fresh water need is for agriculture. Current practices and technologies in managing water streams are not enough in the future.
\end{abstract}

Water scarcity will mean ever rising water cost for individuals, enterprises and communities. Investments are needed to provide the increasing population access to safe fresh water. Innovations are needed both for improving water efficiency in agriculture, industry and in households likewise for making more fresh water available in areas of water scarcity. Improving water efficiency of the main use segment, agricultural production, is a fundamental challenge. The water efficiencies of industrial processes, representing one fifth of the total, are improved as water cost rises and as environmental regulations are better enforced. Efficiency of household and community use of water, representing one tenth of the total can be improved with rather simple means: reducing wastage and leakage.

This article discusses the reasons and consequences of fresh water scarcity, but also highlights existing and potential solutions for sustainable water processes. In the context of this article sustainability means minimizing harmful impacts to environment and providing wellbeing to people while continuously offering opportunities for business development. Scientific research is needed for developing new technologies. Industrial companies are essential in taking the new technologies in use by converting these into business opportunities. Public sector is in the key role in providing infrastructure and supporting legislation. As development and investment cycles are long, tight cooperation of all parties is essential.

\section{Towards Sustainable Water Processes}

Even though our Earth is practically covered with water, megatrends of population growth, urbanization and global warming make it more and more difficult to find clean water for our needs. Most experts estimate, that today, on the second decade of the 2000's, the global need of fresh (low salt content) water is equal to the globally available fresh water. So things seem to be in balance now. But we should not forget the growth: Demand of fresh water has been rising globally with a couple of percent points per year. This is expected to continue. And the other side of the equation there's the fresh water supply, which remains more or less constant. A modest 3\% annual growth rate means that 10 years from now we have a global fresh water shortage of over 30\%. Moreover, the global averages don't tell us much: In certain areas water availability has already for decades been severe, even critical. Due to 
population growth and urbanization it will be a major problem for even bigger part of the population and ecosystem than the average demand growth suggests. And at the same time other areas, due to increasing precipitation, will be practically drowning in fresh water. The sad fact is that most severe fresh water problems are experienced in poorest areas. This is a major obstacle for improvement. Supply - demand equation must be balanced on global and regional levels, otherwise the water processes are far from sustainable.

\section{The big water purifier}

The water problem seems incomprehensible, considering that earth is almost covered with water. But it's not that simple: Seawater, comprising $97.5 \%$ of all global water is unfortunately not so easy to use for quenching our thirst. Removing dissolved salts from seawater requires lots of energy. Vast majority of unsalted water is in glaciers, so only a tiny fraction of our water is currently usable liquid water. These surface and ground water bodies are constantly fed by Mother Nature's own solar-powered water purification cycle (evaporation/precipitation/soil+vegetation filtering) at relatively constant rate. But the global warming seems to amplify the extreme conditions, such as droughts and floods. Urbanization and most construction activities decrease the natural vegetation and increase erosion. This all reduces the natural filtering and storing of fresh water. The effects of extreme conditions and erosion are dramatic, ranging from desert expansions to mud floods. And many agricultural or industrial activities make the situation even more serious: Massive irrigation of cotton plantations practically dried up one of world's biggest lakes, Aral. Uncontrolled wheat farming and field tilling of US Great Plains in 1920's resulted in a decade of devastating dust storms. Then there's ditch-drying of swamplands and exploitation of underground aquifers. Also beyond these widely known example cases the risk list for earth's clean water service is alarmingly long.

\section{The DEMAND side of the equation: Smarter irrigation needed}

Two thirds of fresh water is used for growing food, mostly for irrigation. Increasing standard of living normally (perhaps sadly) means more processed, meat based diets, which again amplify the need of water. So it's clear that major impact on global fresh water need is in finding smarter and more efficient ways to provide water for food and feed production. Producing meat consumes much more water than equal energy portion of edible plant matter. So favoring vegetable diet eases the water demand problem, but alone it cannot solve it. We need to find more clever means of irrigation. Many such are increasingly used as water price increases: Drip irrigation eliminates harmful evaporation compared to traditional spraying. Irrigation water can be recycled in fields as in greenhouses. Fertigation, combining nutrient addition to smart irrigation, and hydroponic or no-soil farming eliminate the unnecessary wetting of soil, thus saving water. Efficiency improvement is necessary also because the growing renewable fuel crop production further increases the need of irrigation water. In all farming we can and should favor plant species 
with better water economy. And there's nothing wrong speeding this up by modern gene technology.

Production of also other goods than food and drink consumes surprising quantities of water. Industrial fresh water need is estimated at $20 \%$ of the total fresh water. Industrial processes are generally not designed for high water efficiency, as water has not been a cost factor. This has resulted in wastage of fresh water and many times significant damages to the environment. Two current trends are improving the situation: Rising water cost and enforcement of environmental regulations. Water and process stream recycling offer opportunities for water savings - for example a modern paper mill consumes $80 \%$ less water than its father 30 years ago. This has required development of new types of equipment, new chemicals and solutions and innovative process control. Optimally, it's a virtuous cycle: The research work of universities feeds the development work of industrial companies who again channel part of the created value to universities - through taxes or as direct investments.

Municipal water use - public and private water for people and communities comprises the rest of fresh water need, estimated at $10 \%$. The regular water toilet is great for hygiene, but a nightmare for water efficiency. Modern water minimizing flushing systems will provide marginal water efficiency improvement. More dramatic improvement would be achievable by source separation systems, which separate the solid human waste from the liquid already at the toilet seat. Grey water and other domestic recycle systems will be installed more as water cost rises. In many cities the public systems are not reliable enough, so new housing areas will be built for independence and improved efficiency. Water wastage through leaking pipelines and faucets is a severe problem in countless urban areas. Many cities can't afford to repair them. Leak losses in excess of ten percent are not uncommon. So there are lots of challenges. But there's something we all can do: Use common sense in our use of water. Unfortunately common sense seems not to be so common nowadays.

\section{The SUPPLY side of the equation: Sea or rain?}

How can we make more fresh water available? Sea water already is a main source of fresh water in many places e.g. in many areas of Middle East and Spain. There are two main technologies for desalination - producing fresh water from salt water: evaporation of membrane technologies. Both technologies battle with two issues: investment cost and energy need. Modern evaporation technologies have increased their energy efficiency by using multiple effect evaporation in steps of lowering pressure. Membrane technologies utilize pressure differential over thin polymer films to push only the tiny water molecules through. Same rule applies for both technologies: Every step towards energy efficiency increases investment cost. Membrane material development has advanced in big strides: E.g. some industrial products mimic the nature's ingenious semi-permeable membranes. Through increased production the membrane performance to cost ratio increases rapidly. 
Steeply increasing performance to cost ratio of solar power greatly improves both evaporative and membrane technologies. Unfortunately with even the biggest strides it will take decades before desalination gives a significant relief to our badly lopsided supplydemand equation.

Other ideas, even projects, have been proposed. Water will be piped to water stress areas over even greater distances. There have been attempts to turn the flow of rivers (but who can predict the effects of these?). And how about towing icebergs from Antarctic to Dubai?

Perhaps more realistic projects are the ones dealing with "harvesting" rain or humidity. Rain water can - as it should be - collected and stored more efficiently than today. In small scale this can be done at household or community level. Also air contains surprisingly much water as humidity, which can be condensed into liquid on suitable surfaces. This ancient technology can be refined with modern materials and processes.

Also the supply side of water offers new business opportunities as water shortage and cost increase. Private enterprises are needed to turn these opportunities quickly into action. The public sector is a good and eager customer for them, but has limited funds and is typically slow in decision making.

We must also see nature conservation as a solution to the fresh water dilemma. Natural wetlands must be protected and restored to enable natural storage and filtering of rainwater. Trees and vegetation must be planted practically everywhere to stop or slow down erosion. Natural ground water reservoirs, such as the great North American Ogallala aquifer, must be protected or even refilled. The problem with these bigger and very favorable projects is the cost. Who will pay for the projects in the current global economic situation? Or ever?

\section{Conclusion: Opportunities through innovation and investments}

We can't survive without fresh water. This means, that sooner or later we must solve the demand-supply gap to avoid starvation, illnesses and problems related to inequality. Water inequality will trigger unrest, migrations and possibly even wars. The dilemma cannot be solved by politicians or the public sector alone - co-operation with academic research and private enterprises is needed. Developing more sustainable water processes for agriculture is fundamental. Industry, responsible for $20 \%$ of total demand, will develop its water efficiency as water cost rises. Companies - converting ideas into money - are needed to accelerate improvements in water efficiency and innovating new economically viable sources of fresh water. And every one of us can contribute by common sense: Seeking facts about water, technology and economy, by sharing this knowledge and by making fact-based "water conscious" consumption decisions

Even though the situation is challenging, there's a brighter side to it: Water, with its vast challenges, offers endless opportunities for innovation. 